\title{
PROPOSTA DE CENÁRIO GAMIFICADO PARA O AMBIENTE VIRTUAL DE APRENDIZAGEM
}

\section{SCENARIO GAMIFICATED PROPOSED TO THE VIRTUAL LEARNING ENVIRONMENT}

\author{
Katielen Bissolotti ${ }^{1}$, M.Sc. \\ Alice Theresinha Cybis Pereira ${ }^{2}$, Ph.D \\ (1) Universidade Federal de Santa Catarina \\ kaathyie@gmail.com \\ (2) Universidade Federal de Santa Catarina \\ acybis@gmail.com
}

gamificação, protótipo, ambiente virtual de aprendizagem

\begin{abstract}
Através dos games, os usuários passam horas executando tarefas que exigem concentração e dedicação. E com a ajuda dos elementos de games, os jogadores permitem escapar para uma realidade alternativa. Tratar essas questões num ambiente voltado à aprendizagem pode transformar e enriquecer a experiência do usuário. Para isso, expor estruturas que visem um sistema gamificado eficiente, através da correta inserção dos elementos de games nas interfaces educativas vem a contribuir. Dessa forma, este artigo apresenta uma proposta de um protótipo de baixa fidelidade de um ambiente virtual de aprendizagem com os elementos de gamificação, contribuindo no aprimoramento dos processos utilizados no desenvolvimento de hipermídias, recomendando etapas de projeto através da inserção desses elementos. Como resultado, foi possível identificar a necessidade de implementar estratégias que completam a inserção dos elementos e que permitirá contornar obstáculos futuros no desenvolvimento de ambientes de aprendizagem.
\end{abstract}

\section{gamification, prototype, virtual learning environments}

Through games, users spend hours performing tasks that require concentration and dedication. And with the help of the elements of games, players allow escape into an alternate reality. Addressing these issues in a learning environment can transform and enrich the user experience. To do this, exposing structures that aim at an efficient gamified system, through the correct insertion of the elements of games in the educational interfaces comes to contribute. In this way, this article presents a proposal of a low fidelity prototype of a virtual learning environment with the elements of gamification, contributing in the improvement of the processes used in the development of hypermedia, recommending design steps through the insertion of these elements. As a result, it was possible to identify the need to implement strategies that complete the insertion of the elements and that will allow to overcome future obstacles in the development of learning environments.

\section{Introdução}

Existe uma longa história do uso da diversão e dos jogos para motivar as pessoas e tornar o trabalho mais agradável. Desde 2010, o termo gamificação é uma adição recente ao vocabulário, antes disso, há alguns designers e pesquisadores que já trabalhavam com aplicações de informática adicionando games e diversão. Malone (1982), 


\section{$16^{\circ}$ ERGODESIGN USIHC CINAHPA}

$16^{\circ}$ Ergodesign - Congresso Internacional de Ergonomia e Usabilidade de Interfaces Humano Tecnológica: Produto, Informações Ambientes Construídos e Transporte

$16^{\circ}$ USIHC - Congresso Internacional de Ergonomia e Usabilidade de Interfaces Humano Computador

CINAHPA | 2017 - Congresso Internacional de Ambientes Hipermídia para Aprendizagem. criou as "Heuristics for designing enjoyable user interfaces", onde analisou os recursos de sistemas computacionais baseados em três categorias: desafio, fantasia e curiosidade, e que, muito da motivação para a utilização dos sistemas dependem da motivação do usuário para alcançar o objetivo.

Com o desenvolvimento de pesquisas na área de experiência do usuário (UX) - trata da satisfação das necessidades humanas (HASSENZAHL, 2008) - nas últimas duas décadas, os pesquisadores, consideraram o papel da diversão e do jogo nas experiências de usuário. A ideia dessa utilização do lúdico em software, foi que, ao invés de fazer as interfaces simplesmente úteis, ela também poderia ser divertida de usar, provocando emoções e sentimentos positivos através de recursos como som, gráficos e desafios, aumentando assim a experiência de usuário com o software

Assim, com o intuito de avançar na compreensão desse tipo de recursos, este artigo apresenta uma proposta de um protótipo de baixa fidelidade, de um ambiente virtual de aprendizagem com os elementos de gamificação. Buscando-se os mais recentes conhecimentos produzidos sobre o tema, discute-se os conceitos de gamificação, elementos dos games e do design centrado no jogador. Deste modo, com o objetivo de definir variáveis para um estudo comparativo. Vale ressaltar que essa proposta não envolve o restante da hipermídia e sim, a inclusão dos elementos de gamificação no ambiente de aprendizagem.

\section{Gamificação}

O termo em inglês "gamification" (gamificação) foi cunhado em 2002 por Nick Pelling (VIANNA, 2013) um programador de computador e pesquisador de origem britânica, mas só recentemente que pesquisadores iniciaram a abordar o tema.

Gabe Zichermann e Christopher Cunningham, no livro intitulado "Gamification by Design", definiram gamificação como o "processo de utilizar o pensamento e as mecânicas dos games para envolver usuários e resolver problemas" (ZICHERMANN; CUNNINGHAM, 2011, p.16).
Zichermann e Linder (2013) ampliam a definição ainda mais, descrevendo a gamificação como "um processo de envolver o público, aproveitando o melhor de programas de fidelidade, design de jogo e economia comportamental". Um centro de Pesquisa sobre gamificação foi estabelecido depois do workshop realizado na conferência CHI 2011, intitulado "Gamificação: Usando elementos de design de games em contextos não jogados". No mesmo ano, Sebastian Deterding também contribuiu para uma definição acadêmica do termo, o "uso de elementos de game fora do contexto dos games" (DETERDING et al., 2011, p.10).

Huotari e Hamari (2012, p.19) propõem uma nova definição da gamificação, eles descrevem a gamificação como um "um processo de reforço de um serviço com affordances para experiências gameful, a fim de apoiar a criação de valor global do usuário". Essa definição, sem dúvida, é pouco quando comparado as definições apresentadas anteriormente.

Para Kevin Werbach, a gamificação "é o processo de fazer atividades mais game-like" (WERBACH, 2014, p. 266). Ele explica que concebendo a gamificação como um processo, cria-se um melhor ajuste entre as perspectivas acadêmicas e chama a atenção para a criação de experiências game-like, uma das vantagens é que o design persuasivo se conecta com a gamificação.

O dicionário britânico Merriam-Webster (2015) define gamificação, como um "processo de adicionar games ou elementos dos games a algo (como uma tarefa), de modo a incentivar a participação das pessoas".

\subsection{Teoria do flow}

O professor de psicologia, Csikszentmihalyi (1990) define o conceito de fluxo como,

o estado em que as pessoas estão tão envolvidas em uma atividade que nada mais parece importar, a própria experiência é tão agradável que as pessoas vão fazer mesmo que o custo para isso seja grande, para a puro questão de fazê-lo (CSIKSZENTMIHALYI, 1990, p. 4).

Kapp (2012, p.72) apresenta um exemplo de fluxo
Realização:

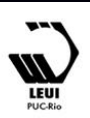




\section{$16^{\circ}$ \\ ERGODESIGN USIHC CINAHPA}

que muitos jogadores já vivenciaram. Ele aborda sobre uma típica noite em que o jogador decide jogar, e de tão imerso, ele perde a noção de tempo, mas tem facilidade com as missões e desafios. Ele está convicto que passará de nível e que nada irá pará-lo. Mais cinco horas, e o jogador percebe que está com fome, não jantou e já é outro dia.

Portanto, o fluxo é um estado mental em que uma pessoa está totalmente imerso e focado no que ele está fazendo; que o envolve mentalmente no processo da atividade. É esse estado ideal entre o tédio e a ansiedade ou frustração (Figura 1).

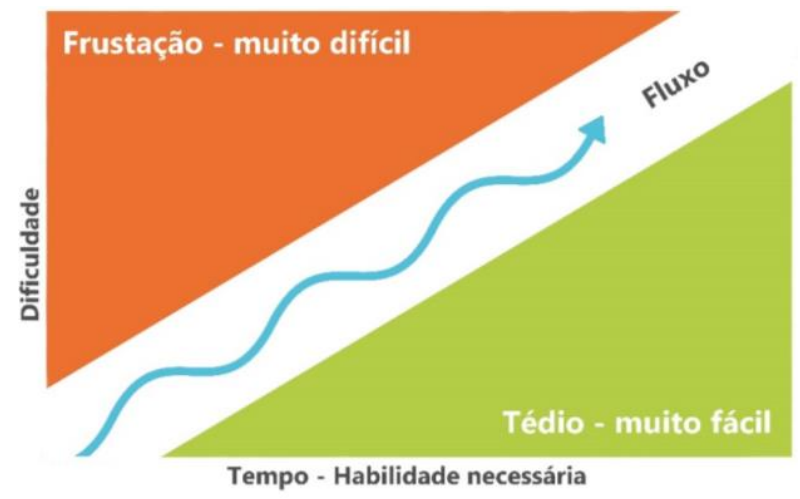

Figura 1 - Fluxo do jogador

O estado de fluxo se caracteriza pelo estado mental de total imersão em uma atividade e cujo objetivo resultará em sucesso e na experiência do jogador. Ou seja, resulta de uma combinação muito especial e equilibrada do desenvolvimento de uma atividade, que nos desafios não é suposto ultrapassar as habilidades, mas também, a atividade não deve ser fácil, para não entediar.

\subsection{Elemento dos games}

Para Jesse Schell (2008) esses misteriosos elementos dos games são "o núcleo do que realmente é o game. Eles são as interações e relações que permanecem quando toda a estética, tecnologia e história são retiradas" (SCHELL, 2008, p.130).

Alguns elementos são iguais em todos os games, mas alguns são mais comuns e influentes na formação de exemplos de gamificação, que começam basicamente com "A Tríade PBL" (The $P B L$ Triad), ou seja, os pontos (points), emblemas $16^{\circ}$ Ergodesign - Congresso Internacional de Ergonomia e Usabilidade de Interfaces Humano Tecnológica: Produto, Informações Ambientes Construídos e Transporte

$16^{\circ}$ USIHC - Congresso Internacional de Ergonomia e Usabilidade de Interfaces Humano Computador

CINAHPA | 2017 - Congresso Internacional de Ambientes Hipermídia para Aprendizagem.

(bagdes) e rankings (leaderboards). E se usados de maneira correta os PBL tornam-se poderosos, práticos e relevantes (WERBACH; HUNTER, 2012). Há três categorias dos elementos dos games que são relevantes para a gamificação. São eles: dinâmica, mecânica e componentes (WERBACH; HUNTER, 2012; ZICHERMANN; CUNNINGHAM, 2011).

DINÂMICAS: São as interações do jogador com os elementos da mecânica (ZICHERMANN; CUNNINGHAM, 2011). Para Werbach e Hunter (2012), as dinâmicas de game com maior nível de importância são:

- Restrições (limitações);

- Emoções (curiosidade, competitividade, a frustração, felicidade);

- Narrativa (uma história em curso);

- Progressão (crescimento e desenvolvimento do jogador);

- Relacionamentos (interações sociais que geram sentimentos, status, altruísmo).

MECÂNICAS: Para Zichermann e Cunningham (2011), as mecânicas são os componentes funcionais do game. Werbach e Hunter (2012), elencam algumas mecânicas importantes para o game:

- Desafios (tarefas que exigem esforço para resolver);

- Competição;

- Cooperação (os jogadores devem trabalhar juntos para alcançar um objetivo compartilhado);

- Feedback;

- Recompensas (benefícios para alguma ação ou conquista);

- Transações (negociação entre os jogadores, diretamente ou através de intermediários).

COMPONENTES: São as instâncias específicas das dinâmicas e mecânicas. Geralmente associadas aos elementos gráficos da interface. (WERBACH; HUNTER, 2012). Alguns deles:

- Avatar;

- Emblemas (representações visuais das realizações);

- Ranking; 


\section{$16^{\circ}$ ERGODESIGN USIHC CINAHPA}

- Níveis (etapas definidas em progressão do jogador);

- Pontos;

- Missões (desafios predefinidos com objetivos e recompensas);

- Gráficos Sociais (representação da rede social dos jogadores dentro do jogo);

- Bens Virtuais.

Os autores Zichermann e Cunningham (2011), Kapp (2012) e Bunchball (2012) elencam vários elementos, que cada um deles definem ser necessário na gamificação. A figura 2, ilustra cada um desses elementos e onde pertencem.

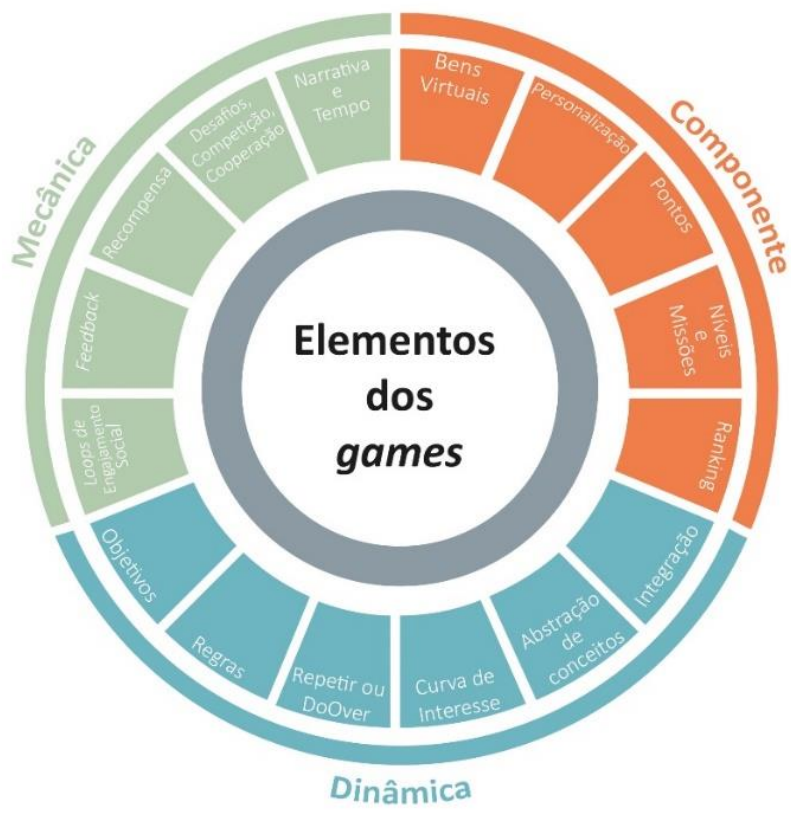

Figura 2 - Elementos dos games

\section{Design centrado no jogador}

Os pesquisadores Janaki Kumar e Mario Herger (2013) conceituam o chamado Player Centered Design, que coloca o jogador no centro do processo de concepção e desenvolvimento a partir dos princípios do design centrado no ser humano. A figura 2 desenvolvida pelos pesquisadores ilustra as etapas desse processo e descreve para ajudar a estruturar o projeto de gamificação. $16^{\circ}$ Ergodesign - Congresso Internacional de Ergonomia e Usabilidade de Interfaces Humano Tecnológica: Produto, Informações Ambientes Construídos e Transporte

$16^{\circ}$ USIHC - Congresso Internacional de Ergonomia e Usabilidade de Interfaces Humano Computador

CINAHPA | 2017 - Congresso Internacional de Ambientes Hipermídia para Aprendizagem.

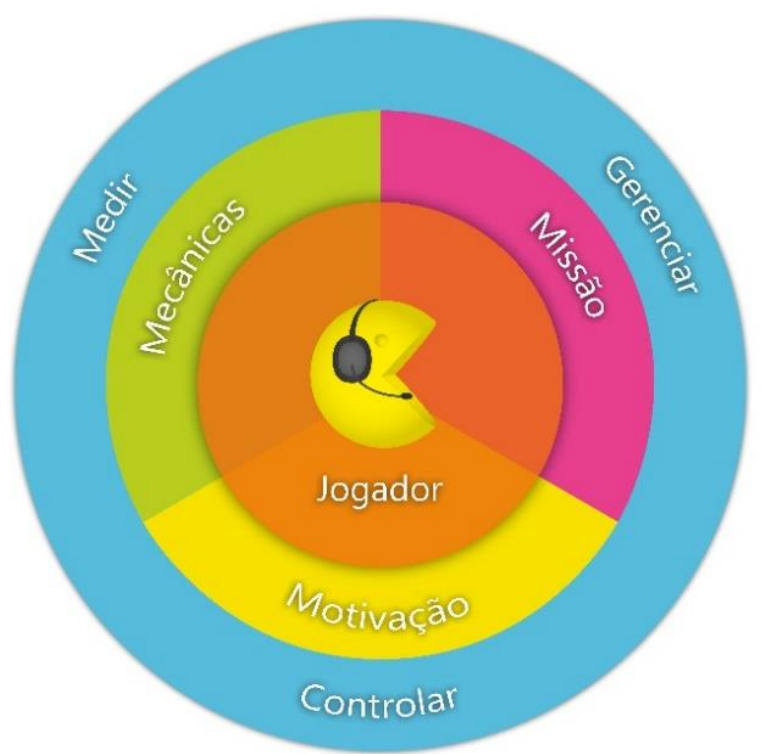

Figura 3 - Processo do Design centrado no jogador

Processo 1: Entenda o jogador: O primeiro passo na abordagem do design centrado no jogador, segundo Kumar e Herger (2013), é compreender o jogador e o seu contexto. O sucesso de seus esforços na aplicação da gamificação depende dessa compreensão clara. Os pesquisadores explicam que para esse sucesso, a estratégia da gamificação necessita estar baseada numa clara compreensão do jogador, assim como no design de experiência, "a gamificação simplesmente não serve uma função utilitária, mas visa engajar, motivar e ser prazerosa, que é semelhante à forma como um designer de games de sucesso se aproxima de seu público-alvo" (KUMAR; HERGER, 2013).

Processo 2: Entender a missão: A missão referese ao objetivo da gamificação no sistema. Esta etapa, para Kumar e Herger (2013) envolve a compreensão do cenário do sistema (o que os jogadores estão fazendo), identifica o resultado desejado, e define uma missão adequada para o projeto de gamificação.

Kumar e Herger relacionam três aspectos importantes para considerar na definição de uma missão eficaz, são eles:

- Compreender o cenário atual;

- Entender o resultado do sistema;

- Identificar uma missão S.M.A.R.T (Specific, 


\section{$16^{\circ}$ \\ ERGODESIGN USIHC CINAHPA}

measurable, attainable, realistic and timebound. Estes elementos são encapsulados na sigla) (KUMAR; HERGER, 2013).

Processo 3: Entender a motivação humana: Os pesquisadores abordam que há uma série de teorias de motivação humana. Eles descrevem dois tipos de motivação, o primeiro como a regra de platina que no caso da gamificação seria como, "não faça aos outros o que não quer que seja feito a você" (KUMAR; HERGER, 2013); e o segundo com a motivação intrínseca, refere-se a motivações internas, tais como autonomia, domínio e significado; e extrínseco, refere-se a técnicas motivacionais externas, tais como dinheiro, troféus, etc.

Conforme os pesquisadores, existem formas gerais para motivar e desmotivar os jogadores, mas a técnica eficaz, irá variar com base no perfil do jogador. Em outras palavras, deve-se "compreender o seu jogador, conhecer sua missão e pensar cuidadosamente sobre qual técnica de motivação vai ajudar o seu jogador de cumprir a missão". (KUMAR; HERGER, 2013).

Processo 4: Aplicar a mecânica de game: De acordo com Kumar e Herger (2013), a "mecânica de game refere-se aos elementos de interface do usuário com o qual o jogador interage como emblemas, pontos, leaderboards e muitos mais". As mecânicas são os elementos mais visíveis numa aplicação gamificada que precisa envolver com o jogador em todo o processo. Os pesquisadores falam que "as mecânicas precisam ser selecionadas com base em uma compreensão completa do jogador, da missão e da motivação humana" (KUMAR; HERGER, 2013).

\section{Processo 5: Gerenciar, controlar e medir:}

Gerenciar a missão é um aspecto importante para assegurar o sucesso dos esforços no sistema gamificado. Kumar e Herger (2013) recomendam planejar outras versões para o futuro e não apenas para o imediato. "A missão poderia permanecer a mesma ao longo de várias versões ou ser modificada para cada versão" (KUMAR; HERGER, 2013). $16^{\circ}$ Ergodesign - Congresso Internacional de Ergonomia e Usabilidade de Interfaces Humano Tecnológica: Produto, Informações Ambientes Construídos e Transporte

$16^{\circ}$ USIHC - Congresso Internacional de Ergonomia e Usabilidade de Interfaces Humano Computador

CINAHPA | 2017 - Congresso Internacional de Ambientes Hipermídia para Aprendizagem.
Controlar a motivação do jogador é importante, pois o jogador fica cansado e controlar essa fadiga se torna essencial. Quando a aplicação gamificada é executada, os jogadores estão engajados e motivados. No entanto, com o passar do tempo, a novidade passa, e o engajamento e entusiasmo do jogador pode desaparecer.

Kumar e Herger (2013) apresentam (Figura 4) o ciclo de vida do jogador desenvolvido pela autora Amy Jo Kim (2012) que segundo eles, descreve o ciclo de vida do jogador em relação ao design do game. Ela refere-se aos jogadores como principiante, regular ou expert com base em sua experiência, e projeta o game apropriadamente em torno de suas necessidades para evitar abandono (KUMAR; HERGER, 2013).

Isso significa que é preciso planejar um roteiro de gamificação, além de considerar o nível de habilidade dos jogadores para sustentar seu envolvimento e prazer (KUMAR; HERGER, 2013).

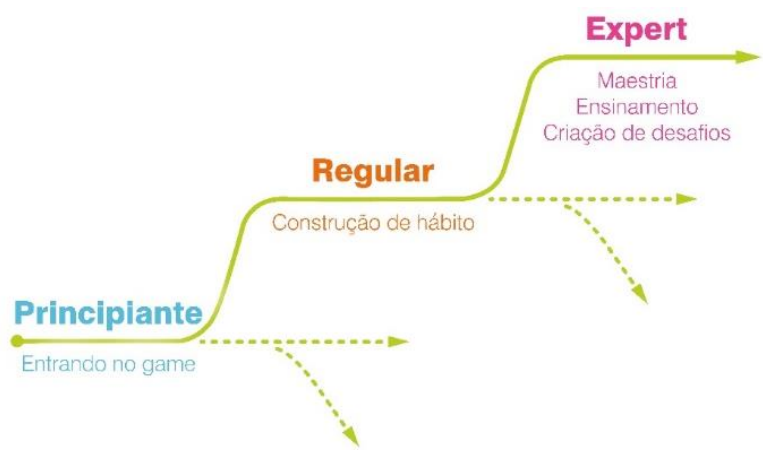

Figura 4 - Ciclo de Vida do jogador

Por último, Kumar e Herger (2013) preferem medir a eficácia da mecânica através de um Brainstorm com a equipe da aplicação para identificar essas métricas, ou seja, os indicadores-chave de sucesso de desempenho da gamificação. Portanto, é importante começar pequeno, acompanhar atentamente os progressos e ajustar conforme necessário. A missão precisa ser gerenciada, a motivação precisa ser monitorada e a mecânica precisa ser medida continuamente. 


\section{$16^{\circ}$ ERGODESIGN USIHC CINAHPA}

\section{Protótipo do Cenário Gamificado}

\subsection{Procedimentos adotados na pesquisa}

Com o intuito de promover a pesquisa-ação, foi realizado o processo de desenvolvimento de um protótipo de baixa fidelidade, do ambiente virtual de aprendizagem com os elementos de gamificação. Entre os elementos desenvolvidos são aqueles mencionados e selecionados na dissertação da autora. Segundo Rogers, Preece e Sharp (2013, p. 391) o "protótipo de baixa fidelidade é aquele que não se parece muito com o produto final". A autora explica ainda que esse tipo de protótipo tende a ser simples, barato e de rápida produção e nunca se destinam como produto final, que serve apenas como exploração de design e ideias.

Deste modo, com o objetivo de definir variáveis para um estudo comparativo, algumas etapas projetuais do projeto foram desenvolvidas por designers e posteriormente enviadas a autora desta pesquisa. Devido a este fato, essa etapa é caracterizada como uma pesquisa-ação, pelo envolvimento da pesquisadora em parte do processo. No entanto, vale ressaltar que essa proposta não envolve o restante da hipermídia e sim, a inclusão dos elementos de gamificação no ambiente de aprendizagem.

Para o desenvolvimento das propostas de gamificação no ambiente virtual de aprendizagem, foram utilizadas as informações propostas pelo grupo de participantes no workshop (ver dissertação da autora), as análises desenvolvidas, assim como os conhecimentos de cada designer participante e da autora dessa pesquisa. $\mathrm{Na}$ próxima seção apresenta-se a ação desenvolvida nessa pesquisa.

\subsection{Concepção da Proposta}

Para a proposta de inclusão dos elementos de gamificação no ambiente de aprendizagem, foi definido alguns elementos: personalização, nível, recompensas, pontos, repetir ou DoOver, feedback, ranking e integração. O processo de concepção e construção das interfaces envolveu uma série de decisões. A primeira delas foi a confirmação dos $16^{\circ}$ Ergodesign - Congresso Internacional de Ergonomia e Usabilidade de Interfaces Humano Tecnológica: Produto, Informações Ambientes Construídos e Transporte

$16^{\circ}$ USIHC - Congresso Internacional de Ergonomia e Usabilidade de Interfaces Humano Computador

CINAHPA | 2017 - Congresso Internacional de Ambientes Hipermídia para Aprendizagem.

elementos de gamificação como recurso satisfatório, agradável, prazeroso, interessante, etc. Esses recursos foram apontados como uma das possibilidades de inserção nas práticas desenvolvidas e explicas na dissertação da autora.

A figura 5 apresenta dois elementos gamificado inseridos no sistema do projeto. Nesta figura, a tela corresponde à visualização da criação de cursos no projeto e os elementos introduzidos aqui também serão vistos nas outras interfaces do projeto. $\mathrm{O}$ primeiro elemento incorporado ao sistema é o Nível (A), que mostrará ao jogador onde se encontra na experiência do sistema e ainda conta com uma barra de progressão informando a contagem dos pontos para alcançar o próximo nível.

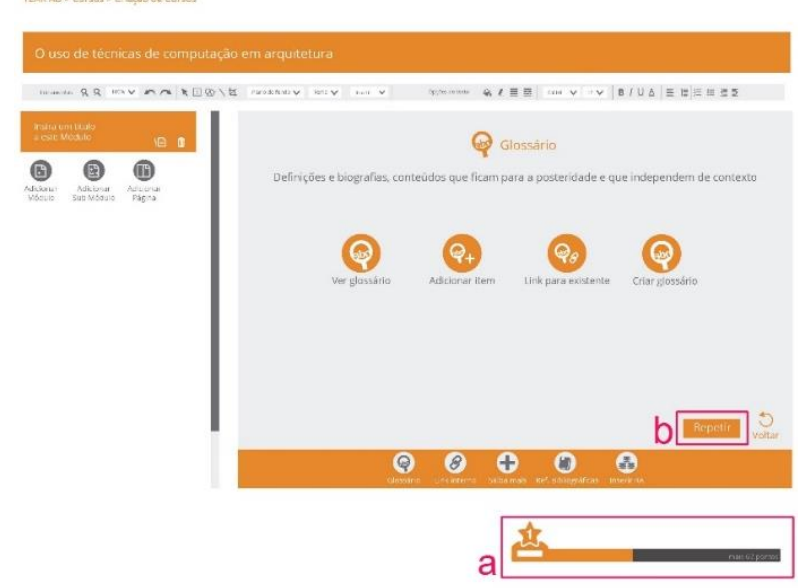

Figura 4 - Interface do ambiente de aprendizagem com elementos gamificados

O segundo elemento incluído ao sistema é o Repetir ou DoOver (B) (Figura 4), o elemento foi inserido pois traz ao jogador a permissão que o mesmo falhe na atividade em andamento. Essa opção é válida, pois o "fracasso é uma opção, que [..] incentiva a exploração, curiosidade e a aprendizagem baseada em descoberta" (KAPP, 2012, p. 57). Aqui, acrescentou-se o botão "Repetir" ao lado do botão "Voltar", essa preferência estará inserida em Cursos, Atividades e Objetos de Aprendizagem do sistema.

No perfil do jogador (Figura 6) foram inseridos cinco elementos. Os pontos $(A)$ adquiridos pelo jogador são visualizados no formato de total
Realização:

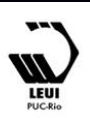




\section{$16^{\circ}$ \\ ERGODESIGN USIHC CINAHPA}

conquistado. Há ao lado do quadro do Ranking dois links, o primeiro é uma tabela sobre os pontos, informa ao jogador como conquistá-los; o segundo é mostrado a tabela dos níveis (Figura 9). Outro elemento é a personalização (B) do avatar do jogador, tem a possibilidade de editar a foto do perfil.

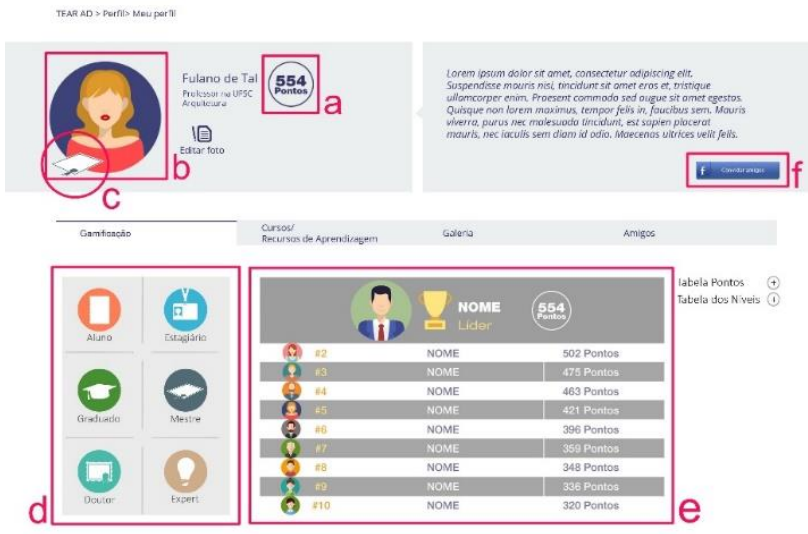

Figura 6 - Interface do ambiente de aprendizagem com elementos gamificados

A Recompensa $(C)$ recebida pelo jogador são troféus do nível conquistado. Zichermann e Cunningham (2011) afirmam que as recompensas são excelentes na forma de incentivo. Na tela projetada para o sistema (Figura 6), recompensas, pontos e níveis estão relacionados. Pois, quando o jogador conquista determinado número de pontos, passa a pertencer ao nível correspondente (Ver figura 9), cada Nivel (D) tem seu nome e um troféu (badge). Na figura 7 ilustra-se esse processo.

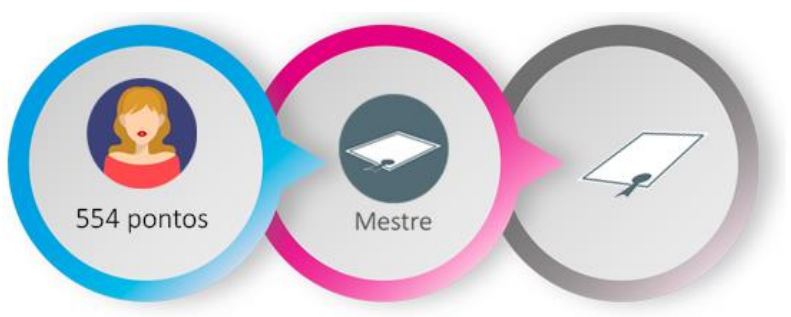

Figura 7 - Visualização do processo Pontos, Nível e Recompensas

O Ranking (E) é uma lista das melhores pontuações no sistema. No quadro é destacado o "Líder" com a maior pontuação, seguindo do $2^{\circ}$ ao $16^{\circ}$ Ergodesign - Congresso Internacional de Ergonomia e Usabilidade de Interfaces Humano Tecnológica: Produto, Informações Ambientes Construídos e Transporte

$16^{\circ}$ USIHC - Congresso Internacional de Ergonomia e Usabilidade de Interfaces Humano Computador

CINAHPA | 2017 - Congresso Internacional de Ambientes Hipermídia para Aprendizagem.

$10^{\circ}$ Colocado. $\mathrm{O}$ último elemento gamificado inserido ao perfil do jogador (Figura 6) é a Integração $(F)$, que é a ação de trazer um novo jogador ao sistema. No protótipo foi inserido o plugin da rede social Facebook, com um botão de convidar amigos, que possibilitará selecionar os amigos do jogador da sua rede social e chamar para conhecer o ambiente de aprendizagem.

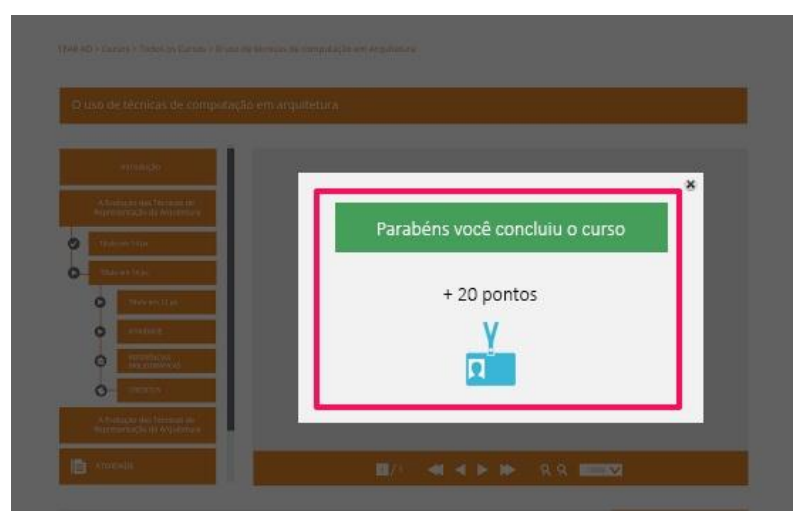

Figura 8 - Interface do ambiente de aprendizagem com elementos gamificados

Na figura 8 é identificado o último elemento inserido no processo de desenvolvimento dos protótipos de baixa fidelidade do ambiente virtual de aprendizagem com elementos gamificados. $\mathrm{O}$ Feedback em aprendizagem ou em games é projetado para evocar o comportamento certo ou ações. É indicado o grau de acerto ou erro numa resposta ou ação (KAPP, 2012). É desenvolvido para que no sistema de aprendizagem o jogador receba o resultado de uma ação ou atividade, informando a quantidade de pontos conquistados e caso de ganho de uma recompensa, o mesmo é mostrado aqui, para após fixar a recompensa na foto do perfil do jogador (Figura 6).

No do ambiente de aprendizagem haverá também outras formas de inclusão do feedback: mensagens de alerta ao jogador (Figura 9), mensagens positivas e também mensagens negativas.

Realização:



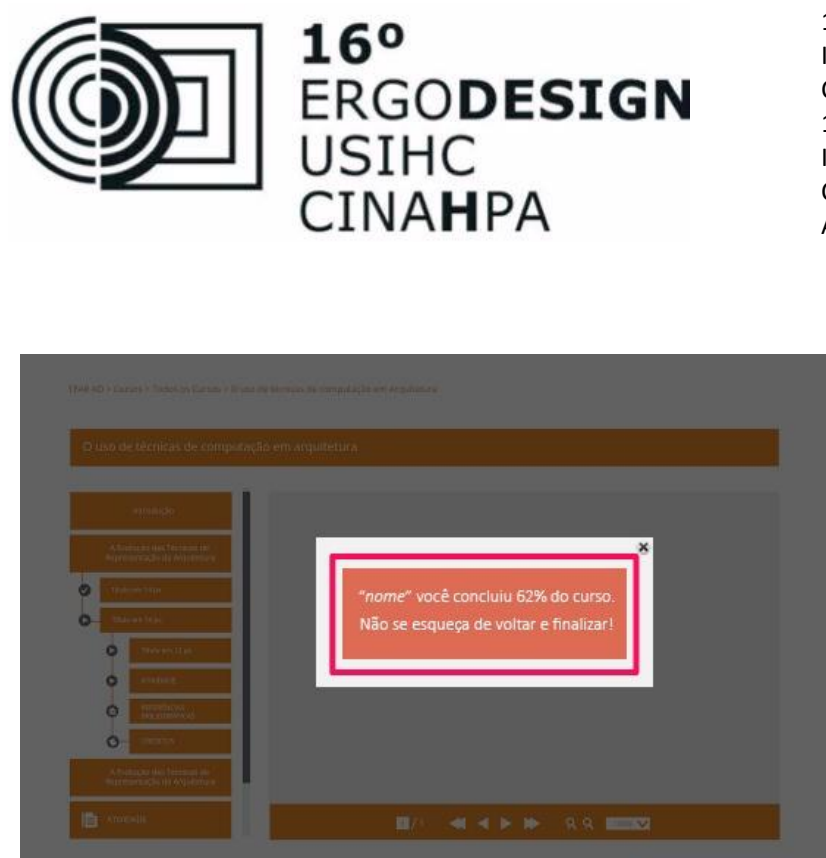

Figura 9 - Interface do ambiente de aprendizagem com elementos gamificados

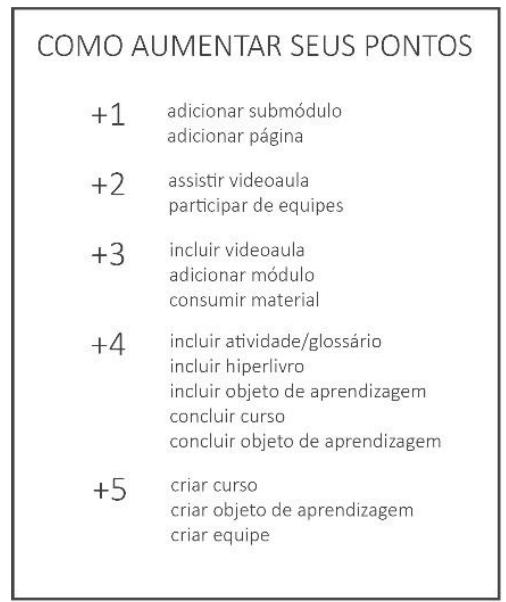

\begin{tabular}{|c|c|c|c|c|}
\hline Níveis & & ont & & Recompensa \\
\hline 1 & 1 & $\sim$ & 100 & Aluno \\
\hline 2 & 101 & $\sim$ & 200 & Estagiário \\
\hline 3 & 201 & $\sim$ & 300 & Estagiário \\
\hline 4 & 301 & $\sim$ & 400 & Graduado \\
\hline 5 & 401 & $\sim$ & 500 & Graduado \\
\hline 6 & 501 & $\sim$ & 600 & Mestre \\
\hline 7 & 601 & $\sim$ & 700 & Mestre \\
\hline 8 & 701 & $\sim$ & 800 & Doutor \\
\hline 9 & 801 & $\sim$ & 900 & Doutor \\
\hline 10 & 901 & $\sim$ & 1000 & Expert \\
\hline
\end{tabular}

Figura 10 - Tabela dos pontos e níveis

Por fim, essa última imagem (Figura 10), representa as tabelas de consulta do jogador, dessa forma será possível conhecer o procedimento dos $16^{\circ}$ Ergodesign - Congresso Internacional de Ergonomia e Usabilidade de Interfaces Humano Tecnológica: Produto, Informações Ambientes Construídos e Transporte

$16^{\circ}$ USIHC - Congresso Internacional de Ergonomia e Usabilidade de Interfaces Humano Computador

CINAHPA | 2017 - Congresso Internacional de Ambientes Hipermídia para Aprendizagem. ganhos da pontuação e qual nível enquadra-se tal pontuação e a recompensa a conquistar.

\section{Considerações Finais}

De acordo com o estudo realizado, as principais contribuições deste trabalho diante da proposta do protótipo de baixa fidelidade, foi o levantamento das percepções da prática experimentada no desenvolvimento das interfaces que estimulou e favoreceu a reflexão e avaliação da inclusão desses elementos em ambientes de aprendizagem. Identificou-se que os principais elementos gamificados são aqueles diretamente associados à experiência do jogador no sistema.

Como melhorar o envolvimento do usuário com o sistema, tornou-se um desafio essencial na concepção de ambientes inteligentes. E com a gamificação é uma nova solução para um melhor envolvimento com os usuários

Dessa forma, foi identificado a necessidade de implementar estratégias que completam a inserção dos elementos e que permitirá contornar obstáculos futuros no desenvolvimento. Tais estratégias estão relacionadas com o desenvolvimento do ambiente de aprendizagem; do monitoramento dos elementos inseridos junto aos jogadores; do gerenciamento das mudanças, caso seja necessário (inclusão de mais elementos, mudança nos tipos de níveis, pontos, etc.). Destaca-se que essas estratégias descritas são afetadas pelo grande número de acessos no sistema. Todas demais informações se encontra na integralidade disponível na dissertação da autora (2016).

\section{BIBLIOGRAFIA}

BUNCHBALL. Gamification101: An Introduction to the Use of Game Dynamics. 2012. Disponível em: <http://www.bunchball.com/ gamification101>. Acesso em: março 2015.

CSIKSZENTMIHALYI, Mihaly. Flow: The Psychology of Optimal Experience. New York: Harper Collins, 1990. 
$16^{\circ}$ USIHC - Congresso Internacional de Ergonomia e Usabilidade de Interfaces Humano Computador

CINAHPA | 2017 - Congresso Internacional de Ambientes Hipermídia para Aprendizagem.

DETERDING, Sebastian; et al. Gamification: Toward a Definition. In: CHI - Workshop Gamification: Using Game Design Elements in Non-Game Contexts. Vancouver, Canadá, 2011. Disponível em<http:/gamificationresearch.org/wpcontent/uploads/2011/04/CHI_201 1_Gamification_Workshop.pdf $>$. Acesso em: nov. 2014 .

HASSENZAHL, Marc. User Experience (UX): Towards an experiential perspective on product quality. 2008. Não paginado. Disponível em: $<$ http://www.marc-hassenzahl.de/pdfs/hassenzahlihm08.pdf $>$. Acesso em: Mar 2015

HUOTARI K.; HAMARI, J. Defining Gamification - A Service Marketing Perspective. In: 16th International Academic MindTrek Conference, Tampere, Finland, October 3-5, 2012.

KAPP, Karl M. The gamification of learning and instruction: Game-based methods and strategies for training and education. San Francisco: Pfeiffer, 2012.

KIM, Amy Jo. The Player's Journey: Designing Over Time. 2012. Disponível em: $<$ http://amyjokim.com/2012/09/14/the-playersjourney-designing-over-time/>. Acesso em: Mar 2015.

KUMAR, Janaki Mythily; HERGER, Mario. Gamification at Work: Designing Engaging Business Software. Aarhus, Denmark, The Interaction Design Foundation. 2013. ISBN: 97887-92964-06-9. Disponível em:

https://www.interactiondesign.org/books/gamification_at_work.html>. Acesso em: Mar 2015

MALONE, T. W. Heuristics for designing enjoyable user interfaces: Lessons from computer games. In: Conference on Human Factors in Computing Systems - Gaithersburg, Maryland, United States, March 15 - 17, 1982. New York, NY: ACM. Disponível em: <http://www.hcs64.com /files/Malone-Heuristiques.pdf $>$ Acesso em: Jan 2015.

\section{MERRIAM-WEBSTER. Merriam-Webster's} Collegiate Dictionary. Springfield: Merriamwebster, 2015. Disponível em:

$<$ http://www.merriamwebster.com/dictionary/gamification $>$. Acesso em: Jan 2015.

ROGERS, Yvonne; PREECE, Jennifer; SHARP, Helen. Design de Interação: Além da interação homem-computador. 3. ed., Porto Alegre:

Bookman, 2013.

SCHELL, Jesse. The art of Game Design: A book of Lenses. Burlington: Elservier, 2008.

VIANNA, Ysmar; et al. Gamification, Inc.: Como reinventar empresas a partir de Jogos. Rio de Janeiro: MJV Press, 2013.

WERBACH, Kevin. (Re)Defining Gamification: A Process Approach. In: Persuasive technology: 9th International Conference, PERSUASIVE 2014, Padua, Italy, May 21-23, 2014. Disponível em: $<$ http://www.hcibib.org/ Persuasive14>. Acesso em: Dez 2014.

WERBACH, Kevin; HUNTER, Dan. For The Win: How Game Thinking Can Revolutionize Your Business. Filadélfia, Pensilvânia: Wharton Digital Press, 2012. Disponível em:

$<$ https://whartondigitalpress.creatavist.com/forthe win>. Acesso em: Maio 2015.

\section{ZICHERMANN, Gabe; CUNNINGHAM,} Christopher. Gamification by Design. Implementing Game Mechanics in Web and Mobile Apps. Canada: O’Reilly Media, 2011.

ZICHERMANN, Gabe; LINDER, Joselin. The Gamification Revolution: How leaders leverage game mechanics to crush the competition. Chicago: McGraw-Hill, 2013 